\title{
CONGENITAL ELEVATION OF THE SCAPULA: A SERIES OF 18 CASES, WITH A DETAILED DESCRIPTION OF A DISSECTED SPECIMEN.
}

\author{
BY H. A. T. FAIRBANK, IONDON.
}

CASES of congenital elevation of the scapula occur with sufficient frequency to make it advisable that this deformity should be kept constantly in mind. It is a matter of some importance to decide whether a child with an elevated shoulderblade and lateral curvature of the spine is suffering from a congenital or an acquired condition. The prognosis of the two conditions is very different, and often the treatment is dissimilar. Cases falling under the above heading can be arranged into various classes, according to the degree in which the condition differs from the normal, and also according to the presence or absence of other malformations of the skeleton. Apart from the abnormally high position which the scapula occupies, the other conditions frequently met with in association with it are congenital scoliosis (in some cases resulting from the presence of a wedgeshaped half-vertebra), suppression of vertebræ, fusion of ribs, and the occurrence of a cervical rib. Any or all of these latter deformities may occur apart from elevation of the scapula ; but the fact that they are so often met with in conjunction with this abnormal condition of the shoulder makes us look for a common cause. Various explanations have been suggested, viz., malposition of the foetus in utero which prevents descent of the arm (which is said to be really a cervical appendage), deficient liquor amnii, injury during birth, and the influences of atavism. Though these might explain the abnormal position of the scapula in certain cases, none of them can explain the gross abnormalities of vertebræ and ribs, nor the development of a new portion of bone anchoring the scapula to the spine. The only explanation which seems to me to account for all the deformities is that the conditions were the result of faulty segmentation of the mesoblast in early fœtal life. Even this theory does not help us much, for we have no idea what causes this irregular segmentation. Supposing we attribute it to a primary error in the primitive nervous system, a suggestion which I believe has been made without much foundation, we are still in ignorance of the real causation, and we can do nothing to prevent its occurrence. Since Walsham and Willets in I880 published the first detailed description of a specimen which they had dissected, most of the information contained in literature is derived from clinical sources. No excuse is therefore necessary for recording this instance of the deformity which $I$ had the opportunity of dissecting.

\section{SPECIMEN OF CONGENITAL BILATERAL ELEVATION OF THE SCAPULA.}

V. C., female, aged 6 weeks. Died at the Hospital for Sick Children, Great Ormond Street, of marasmus. The specimen shows both scapulæ to lie at an abnormally high level, and to be fixed in an abnormal manner to the vertebral

voL. I. -NO. 4. 


\section{THE BRITISH JOURNAL OF SURGERY}

column. On the right side, the scapula is held to the spine by a cartilaginous bridge. On the left side, the fixation of the scapula is produced by a band of fibrous tissue. In addition, there is gross mal-development of the vertebral column and ribs. The right forearm is included in the specimen, as the radius is absent on this side. The child also had a cleft palate. Below is a detailed description of the muscles, bones, etc., as they were revealed by dissection.

The Muscles.-

Trapezius. - This was deficient to a large extent on both sides. Below the level of the spines of the scapulæ, both were non-existent. Above, the muscles

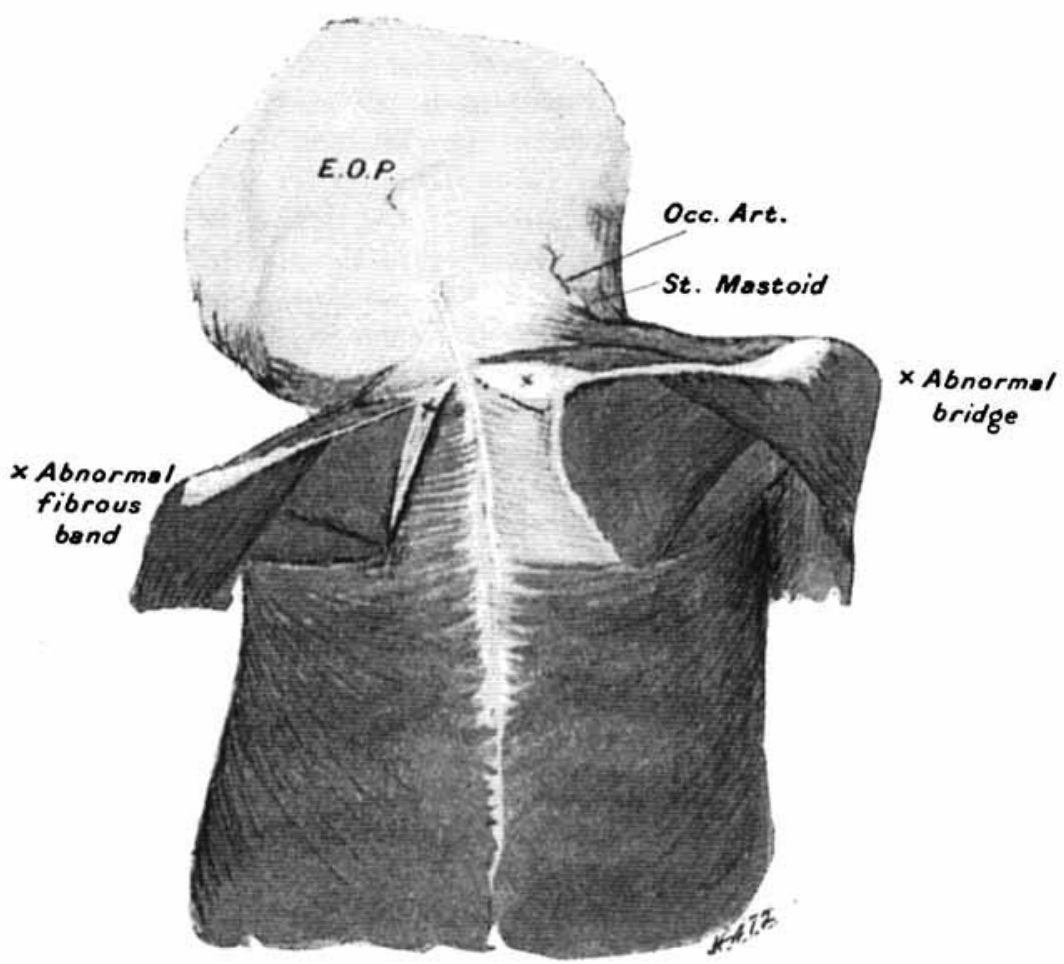

FIG. 355--Dorsal aspect of specimen after removal of skin and iascia, showing irregularities of the first layer of muscles.

were represented by an aponeurosis attached to the inferior curved line of the occipital. From this aponeurosis. muscle fibres arose and passed to the clavicle, acromion, and outer part of the scapular spine. On the right side, other fibres arose from the upper margin of the bridge of cartilage, and passed horizontally outwards to the inner part of the scapular spine. On the left side, these fibres arose from the fibrous band and scapular spine, and passed out to the scapular spine (Fig. 355).

The latissimus dorsi was well developed on both sides. 
Rhomboids. - On the right side, these muscles were represented by an aponeurosis extending from the upper dorsal spines to the vertebral border of the scapula, from the bridge of cartilage above to the angle of the scapula below. On the left side, they were represented by a thin sheet of muscle directly continuous with the latissimus dorsi below, and passing to the scapula deep to the fibrous bridge holding this bone to the spine.

Splenius Capitis. - This muscle on both sides was attached to the skull beneath the sterno-mastoid, and ended below in the bridge of cartilage and the projection from the vertebral border of left scapula respectively.

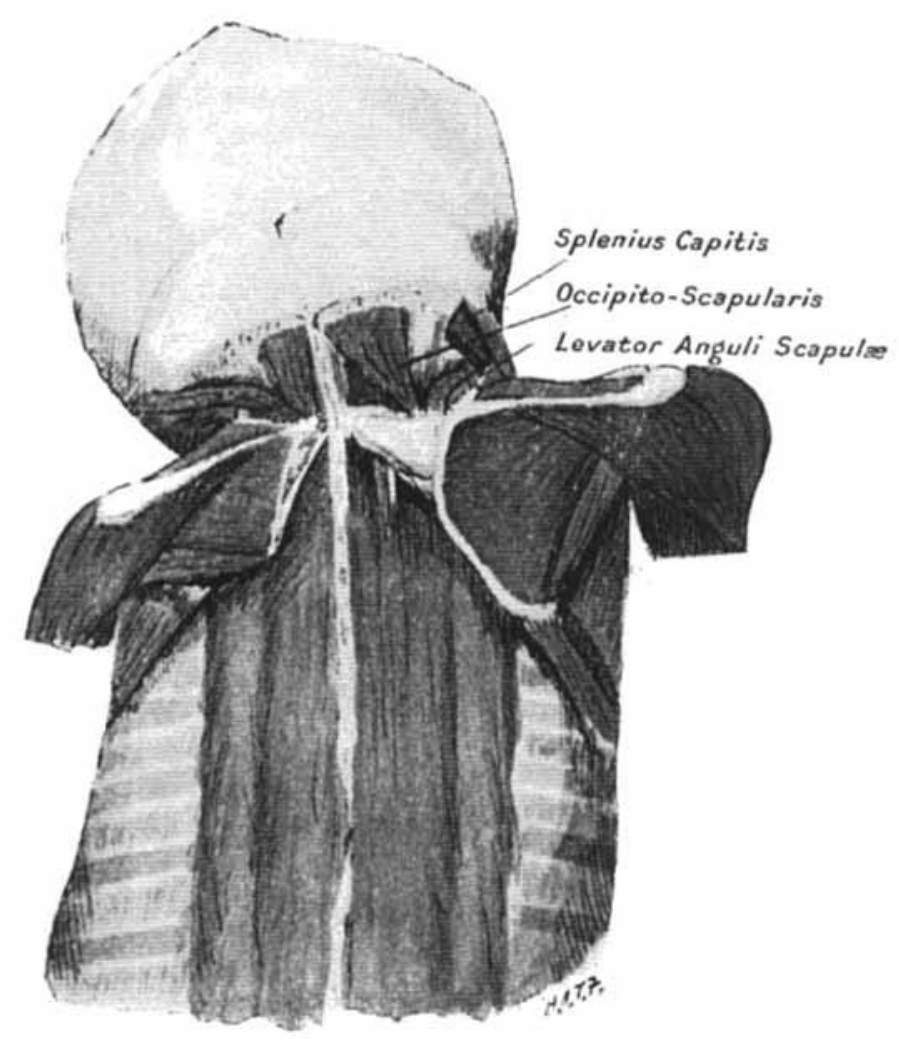

FIG. 356.-Dorsal aspect of specimen, showing deeper muscles.

Trachelo-mastoids.-These, similarly, could only be traced below to the abnormal bridge and cartilaginous projection (Fig. 356 ).

Levator Anguli Scapule.--Normal on both sides.

On each side was found a muscle which should, apparently, be labelled occipito-scapularis. Above, it was attached to the skull just beneath the trapezius aponeurosis above mentioned, from the mid-line outwards for an inch or more. Below, it was attached on the right side to the bridge of cartilage, on the left to the projection of the vertebral border of the scapula (described below). 
The various portions of the erector spince were not differentiated, but it was noticed that the superficial fibres were interrupted by the bridge of cartilage, while the deep fibres passed on beneath it. On the left side some of the superficial fibres were blended with the deep aspect of the fibrous band. The shortness of the neck made it impossible to determine the exact attachment of the recti and other deep muscles. The other muscles attached to the scapula appeared to be normal, except in so far as alteration in their shape and the direction of their fibres was produced by the differences in shape and position of these bones.

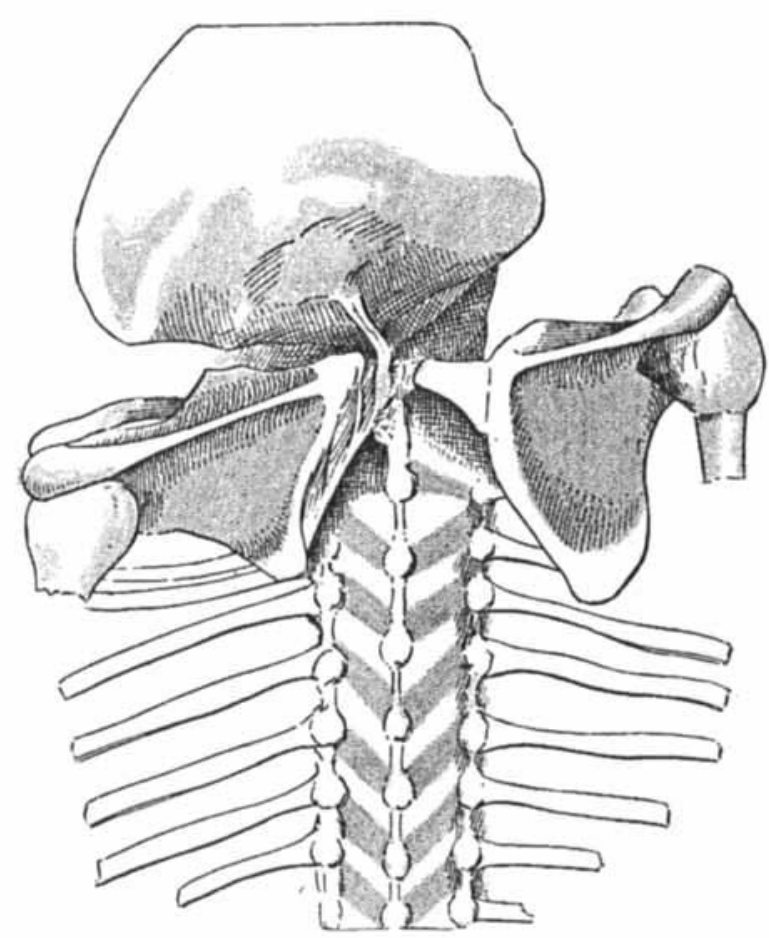

FIG. 357-Dorsal aspect of specimen after removal of all muscies.
The Bones.-

Right Scapula and Bridge.-The right scapula is fairly normal in shape, and shows a good broad band of cartilage along its vertebral border and at the inferior angle (Fig. 357).

The bridge consists of unossified cartilage, triangular in form, with its base at the vertebral border and the apex at the spine. It measures $x^{\circ} 5 \mathrm{~cm}$. from base to apex and I'I cm. at its base. Its base is fixed to the cartilaginous vertebral border of the scapula by a hinge of fibrous tissue. Its apex articulates with the lamina of a lower cervical vertebra. It is impossible to determine the exact vertebra without destroying the specimen. This articulation is brought about mostly by fibrous tissue, but a small joint cavity is present. There is, therefore, some movement possible between the bridge of cartilage and the spine on the one hand, and the bridge and the scapula on the other.

The Left Scapula and its Attachments.-The left scapula is placed nearer to the mid-line and at rather a higher level than the right. The inclination of the head and neck to the left brings the left shoulder in close proximity to the skull. The shape of the left scapula is markedly abnormal. Its vertical measurement is greatly diminished. The vertebral border above the spine slopes markedly outwards to the superior angle, while below the spine it passes downwards and outwards for a short distance, and then nearly vertically downwards. The sloping of the two portions of this border is accentuated by the presence of a cartilaginous projection from the border, opposite the attachment of the spine 
to the scapula. This projection is conical, with a rounded apex, and is directed inwards and slightly upwards towards the spinous processes of the lower cervical vertebræ, to which it is attached a trifle higher than the bridge on the right by ligamentous tissue rather less than a quarter of an inch in length. These fibres form the highest part of a thick fibrous band, which is more or less triangular in outline. Its apex is attached to the lower cervical and upper dorsal spinous processes, while its base extends along the vertebral border of the scapula from the cartilaginous projection above mentioned down to the angle. This fibrous band takes the place of the triangular cartilage of the other side, though it has a much more extensive attachment to the scapula. The spines of the lower cervical and upper three or four dorsal vertebræ appear to be fused, and the lower cervical and rst dorsal are somewhat deviated to the left. The ligamentum nache seems to be continuous with some of the fibres of the ligamentous band passing to the left scapula. The rhomboids, be it remembered, passed beneath this ligamentous band.

The Spine. - The spine displays a marked curve in the cervical and upper dorsal regions, this portion of the spine being tilted to the left

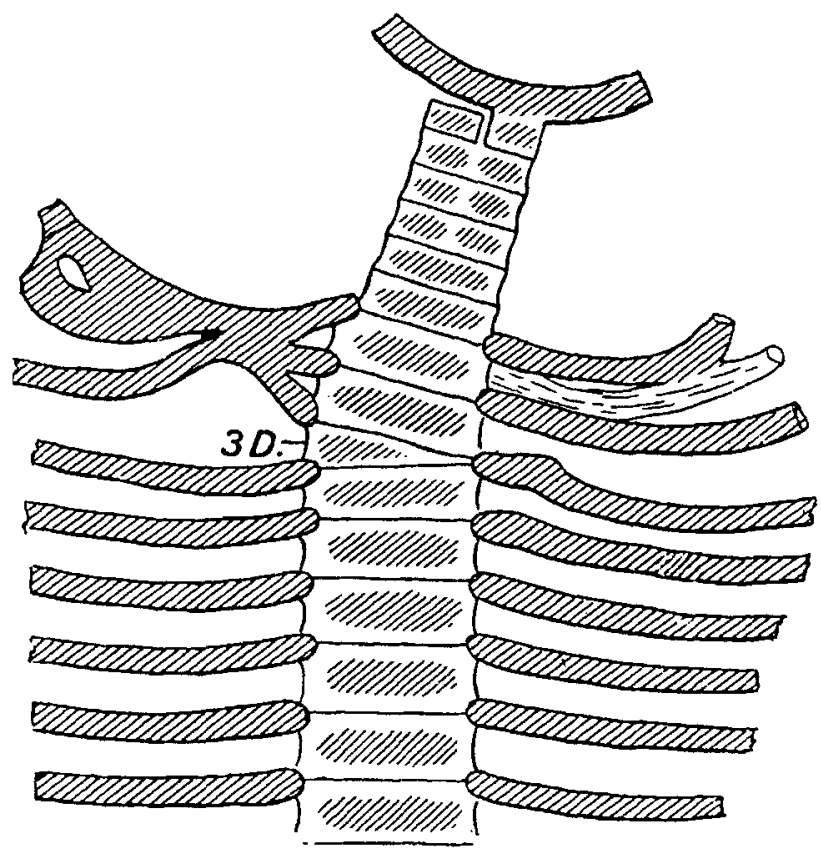

FIG. 358 .-Diagrammatic representation (anterior aspect) of portion of occipital bone, allfthe cervical vertebræ, and most of the dorsai vertebra and ribs. Note half-vertebra, fusion of ribs, etc. owing to the 3 rd dorsal vertebra being wedge-shaped, the right half only being present. Below this point the dorsal spine is straight (Figs. 358 and 359).

Cervical Vertebrce.-Only five of the series can be definitely made out, and in three (possibly four) of these the body is ossifying from two separate centres. Above, the condition seems to be this: the anterior arch of the atlas is divided into two. The left half of the vertebra is fused to the occipital bone, whereas the right half is free. If this interpretation be correct, there are six cervical vertebræ. The lowest displays a distinct attempt at the formation of a cervical rib on the left side, the length of this being nearly half an inch. On the right side, the transverse process is somewhat large and is closely connected with the first rib. Both these cervical ribs can be moved on the vertebra, but it is impossible to say whether this mobility is artificial or not. The neural arches of these vertebræ were not 
completely dissected, but, as already stated, the lower spinous processes were fused and slightly deflected to the left.

Dorsal Vertebra. - - There are portions of eleven dorsal vertebræ in the specimen, and there is no reason to doubt that the twelfth was present, but it was not preserved. The third is only represented by a wedge-shaped body situated well to the right of the mid-line and, so to speak, squeezed from its proper position. The left half of this vertebra is absent. The rest of the dorsal vertebræ are normal. The laminæ of the first three and a half vertebræ are interesting. On the right side there are four laminæ, the first two being very shallow and fused, while the third is joined to the second by cartilage. On the left side the first is fairly normal ; the second is very narrow and fused to the first, and the third is very broad and is probably formed by a fusion of three and four. The left transverse process of the

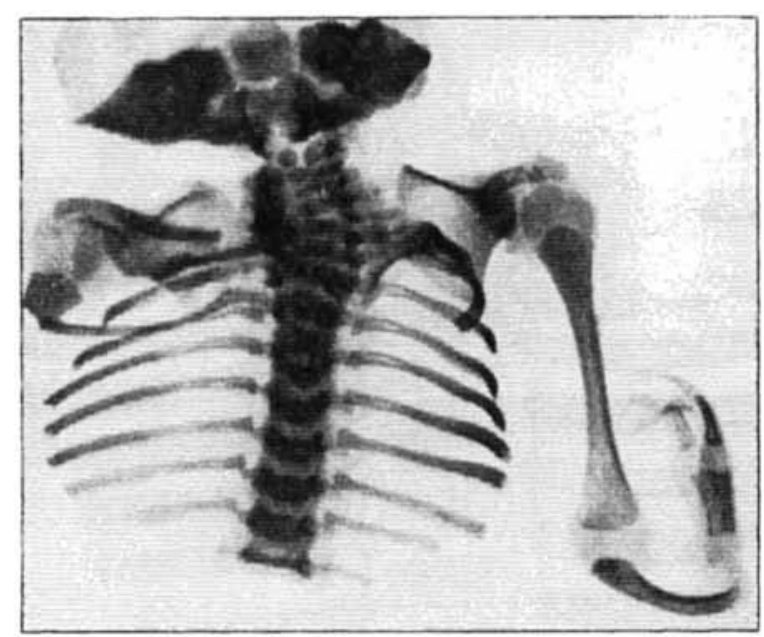

FIG. 359.-Radiogram of specimen, showing two centres of ossificationj of the centra of some of the cervical vertebræ, absence of the right radius, etc. second is minute. The third left transverse process is large, and has the third and fourth ribs articulating with it. The partial suppression of the left lamina and transverse process of the second vertebra confirms the opinion that the cartilaginous bar second in the series of ribs should be regarded as the second true rib.

Right Ribs. - On the right side there are portions of eleven ribs. The upper three are attached to the first two and a half vertebræ respectively, and are partially fused, as seen in the sketch. The portion forming the head and neck of each is separate. The first and second are otherwise fused in their whole length, except for a foramen near the anterior end. The third fuses with the other two for a short distance, and then runs as a separate normal rib. The other ribs in the specimen are normal, as far as can be made out. None of them have been removed entire.

Left Ribs.--On the left side there are ten ossified ribs in the specimen, and in addition a fibro-cartilaginous bar lies second in the series. The first has a prominent head and a very broad extremity, the outer margin of which is fused with the cartilaginous second rib for three-quarters of an inch. The second rib is represented by fibrous tissue near the spine; it then becomes cartilaginous, and is fused for a short distance with the first rib as described above; beyond this fusion it is cartilaginous for a quarter of an inch, and then becomes fibrous again. Unfortunately the connection of this rib with the spine was partly destroyed in removing the soft parts, so that its exact connection cannot be 


\section{CONGENITAL ELEVATION OF SCAPULA}

determined; but its fusion with the outer border of the first rib places its position in the series beyond doubt. The next rib articulates with the bodies of the first and second dorsal vertebræ, and would therefore be labelled the second thoracic rib, were it not for the presence of the cartilaginous rib described above, which lies between it and the undoubted first thoracic rib. The third left ossified rib, regarded as the fourth true rib, articulates with the bodies of the second and fourth vertebræ. Between this and the last rib described, there is no sign of any other rib. But for the presence of the cartilaginous second rib the numbering of the ribs would have been easy enough, allowing for the suppression of the third one on the left, corresponding to the missing half vertebra. A careful examination of the specimen shows, therefore, that while it is the left half of the third dorsal vertebra which is entirely suppressed, it is the second rib which is imperfectly developed. The other ribs seem to have normal attachments to the spine.

\section{Other Points of Interest in the Specimen.- \\ The Head.-The head is} tilted well over to the left, being much nearer to the left shoulder than the right, i.e., there is torticollis.

The Shoulder-joints.-These are apparently normal.

The Right Radius is ,entirely absent, the hand being bent towards the radial side at a right angle with the forearm.

The Thumb and its metacarpal bone are absent. The carpal bones were not investigated, though the radiogram rather suggests that the scaphoid and trapezium are present. (This specimen is now in the

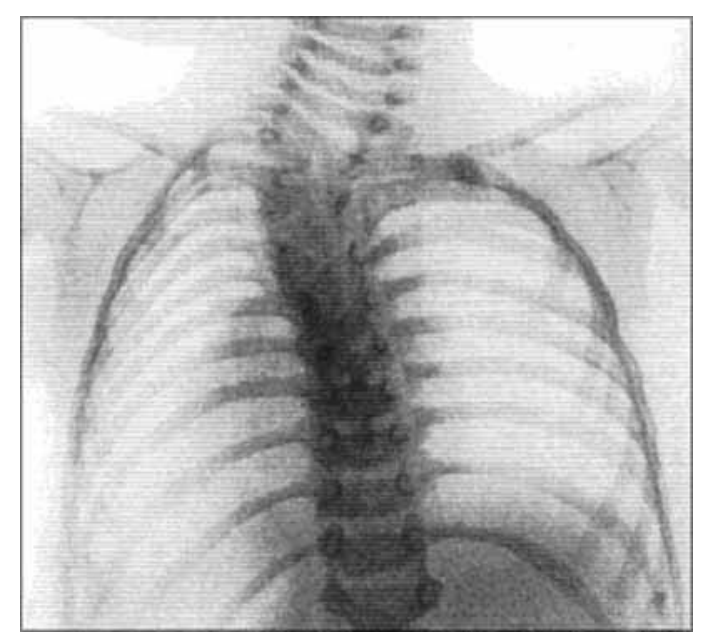

FIG. 360.-Boy, age 2. Congenital scoliosis. (?) Halfvertebra, partial fusion of ribs, scapulæ level and not elevated.

Museum of the Royal College of Surgeons, London.)

This case is, therefore, one of extreme departure from the normal, but, as is well known, there are many cases which, though included under the title of this paper, are very much less complicated.

Besides the case recorded above, I have notes of seventeen others, among which are instances of each variety of the deformity. To indicate the practical importance of diagnosing these cases, and of deciding to which class they belong. we may now pass in review this series, commencing with the least deformed and ending with the class of which the case above is a good example.

As already stated, the presence of a curvature of the spine not uncommonly leads to the true nature of the case being overlooked. Everyone is familiar with cases of scoliosis in which one shoulder is raised above the level of the other, usually on the side of the dorsal convexity. Very much less familiar are the cases of congenital scoliosis with the shoulders level. Fig. 360 is a radiogram of 
such a case. It represents the condition of a boy, aged $2 \frac{1}{2}$, sent to me by Dr. Panckridge, of Petersfield. It will be seen that there is a short, abrupt cervicodorsal curve to the left, with considerable indefiniteness of the upper dorsal vertebræ, and the possible presence of a half vertebra on the left side, representing the third dorsal segment. On the left side there are thirteen ribs, the highest being a cervical rib; on the right side, the upper ribs showed gross irregularity, but it appears that the Ist and 2 nd, 3 rd and 4 th, and $5^{\text {th }}$ and 6 th, respectively, are partially fused. In this boy the scapulæ were level. There was some rotation to the left, with slight prominence of the $2 \mathrm{nd}, 3 \mathrm{rd}$, and 4 th ribs behind. The $3 \mathrm{rd}$, and to a less extent the 4 th, right ribs projected in front, a condition made more obvious by a marked depression of the anterior end of the and rib and its cartilage. This irregularity of the ribs in front, which, by the way, was the deformity for which he was sent to me, coupled with the abruptness of the spinal curve, at once

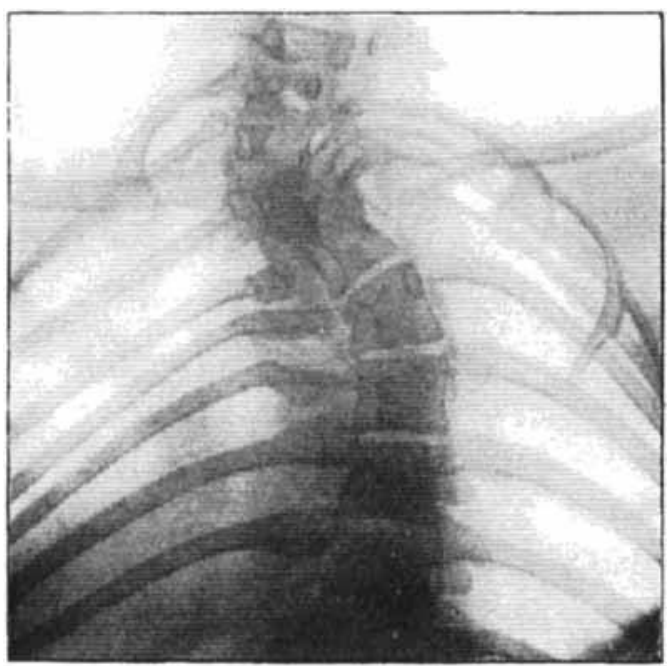

Fig. 36r.-Female, age 2r. Congenital scoliosis with secondary curves, and acquired elevation of left scapula. suggested the advisability of having a radiogram taken to decide the exact condition present. Two other features which often serve to distinguish congenital from acquired scoliosis, namely, rigidity of the curved portion of the spine and flattening below the curve, were both absent in this case.

Fig. $36 \mathrm{I}$ is that of a young lady, aged $2 \mathrm{I}$, sent to me by Dr. Salmon, of Bodmin, for spinal curvature. The suggestion had been made that it might be a case of so-called Sprengel's shoulder. On examination, the last two cervical and first dorsal spinous processes were found to be very prominent, while the sixth dorsal also stood out; the spine between these two points was flattened, almost excavated, and very rigid.

There was a right-dorsal left-lumbar scoliosis, with a fair amount of rotation to the right in the dorsal region, and only slight rotation to the left in the lumbar. The left breast was more prominent than the right, but the highest ribs in front on the right projected more than those on the left. The right scapula was elevated and markedly " winged," but was of normal size and shape, and its mobility was unimpaired. The radiogram shows a very abrupt curve, convex to the left in the upper dorsal region, with loss of definition of the vertebral segments suggesting the possibility of fusion of vertebræ in this region. The upper ribs on both sides are irregular. I believe the correct interpretation of the case to be that there was originally a congenital curve in the cervico-dorsal region, that an ordinary right-dorsal left-lumbar scoliosis developed secondarily, and that the elevation of the right shoulder resulted from the acquired rotation backwards of the right ribs. This was suggested by the history, and was supported 


\section{CONGENITAL ELEVATION OF SCAPULA}

by the fact that the scapulæ were rapidly brought to the same level by a course of remedial exercises.

We now pass to the cases of true congenital elevation of the scapula. I prefer this name to the common one of Sprengel's shoulder, because Sprengel ${ }^{2}$ was not the first to describe the condition, which was recognized by Eulenberg some twenty - eight years previously, while Willet and Walsham's case was published eleven years before Sprengel's article appeared. As a rule, the scapula in these cases is shorter from above down, and generally misshapen, lies nearer to the spine than its fellow, and is considerably restricted as to its movements, in addition to occupying an elevated position.

Even in the cases without fixation of the scapula to the spine by an abnormal bridge, it is the imperfect mobility of the scapula which forms such a distinctive feature (Figs. 369, 373). On raising the arm, the elevated scapula does not move outwards like the one on the other side, and its lower angle does not rotate as it should as the arm is raised above the horizontal. Complaint is usually made by the parents of the asymmetry of the shoulders, and not on account of any disability of the arm, though occasionally weakness or disinclination to use the $\operatorname{limb}$ is mentioned.

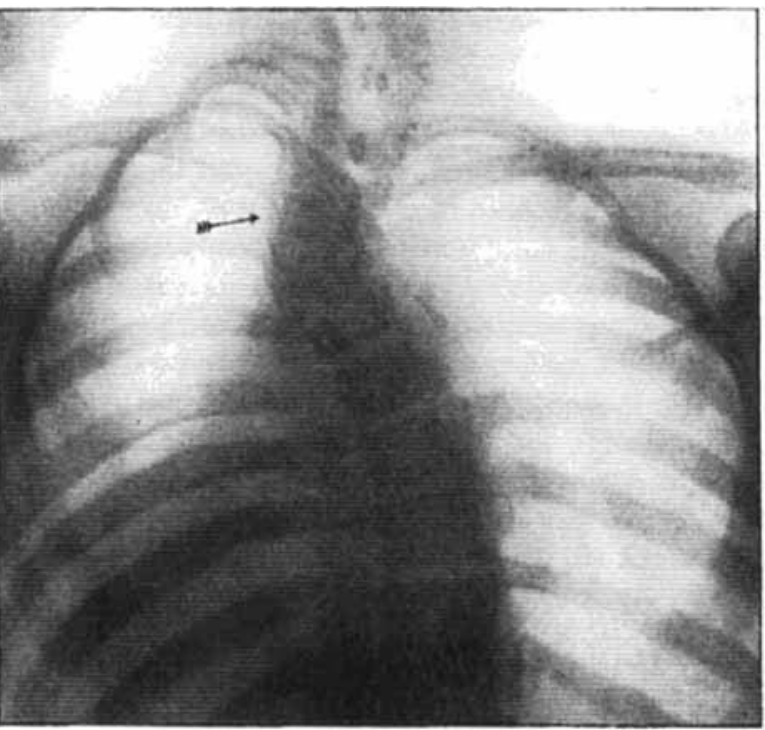

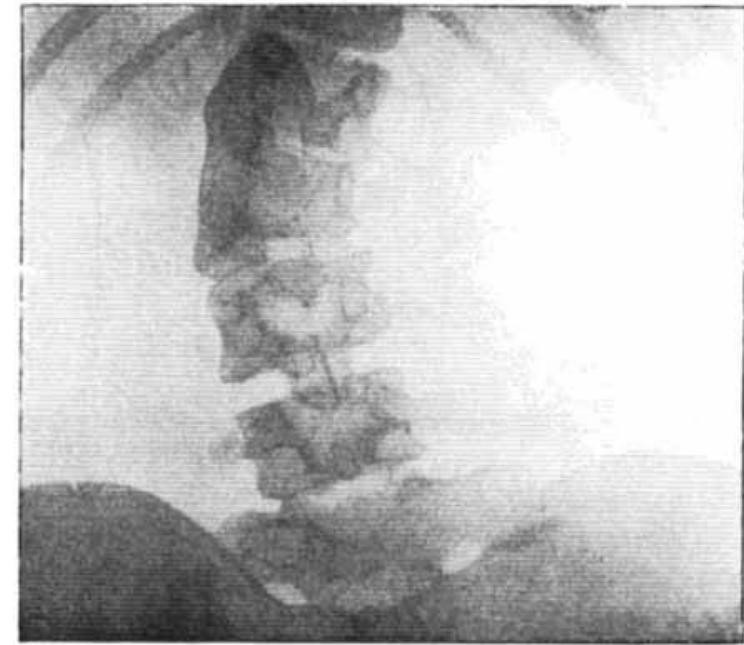

FIGs. 362 and $362 a$.-Congenital scoliosis with elevated scapula, normal in shape and mobility. Girl, age 17 . Curve in upper dorsal region and another in lumbar region. $3 \mathrm{D}$ vertebra wedge-shaped. $2 \mathrm{~L}$ abnormal. Partial fusion of ribs.

All movements of the arm

are possible, except complete elevation to the vertical position. Only one case has been met with in which, though the elevation of the shoulder really 
seemed to be congenital, yet the scapula was well formed and normally mobile. A girl of 17 , a patient of Dr. Renton, of Dartford, displayed an abrupt curve with rotation in the upper dorsal region to the left, and another sharp curve with rotation, also to the left, in the lumbar region. Between these two curves there was only a slight curve to the right, the feature of the middle and lower dorsal region being an abnormal flatness. The left scapula was distinctly elevated, but it was not in any way fixed. The projection of the left ribs behind was above the centre of the scapula, and would not by themselves cause elevation of that bone. It is open to question whether this case should be classed with the others, in all of which the scapula was restricted in its movements; but since there is nothing to indicate how the scapula could have acquired this abnormal position, it is, I think, fair to assume that its displacement is congenital. The condition of the vertebræ and ribs in this case is seen in Figs. 362 and $362 a$. The abrupt high dorsal curve would seem to be due to the third dorsal vertebra being wedgeshaped, its right half, together with the corresponding third right rib, having been entirely suppressed. The lumbar curve is not so obviously congenital, but it is peculiarly abrupt for an acquired curve, considering the slightness of the curve to the right in the dorsal region, while the shape of the second lumbar vertebra suggests congenital abnormality. It will also be noticed that, in addition to the absence of one rib on the right-the third, it is believed--the fifth and sixth right ribs are partly fused, as are also the third and fourth left.
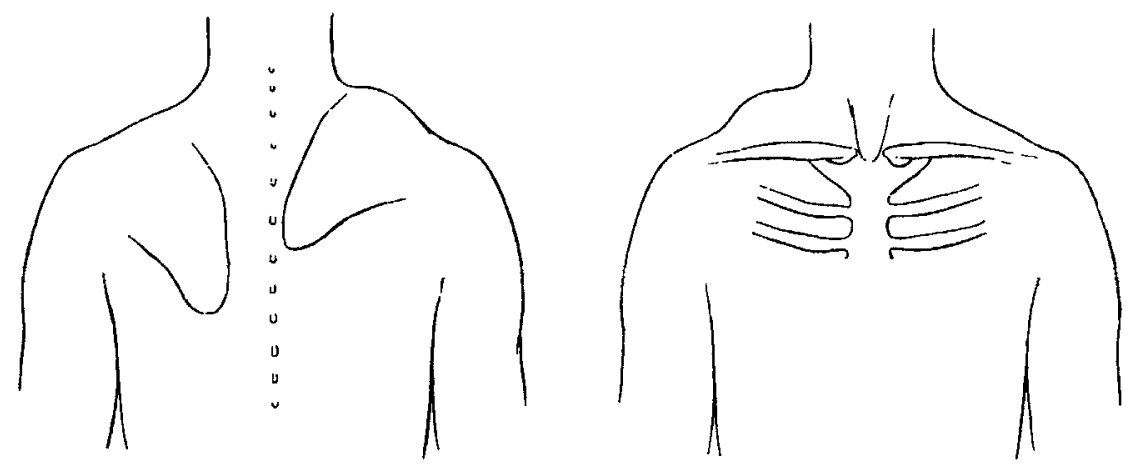

F1G. 363.-Woman, age 23. Congenital elevation of right scapula without abnormality of vertebræ or ribs.

We next pass to cases showing an almost normal, though elevated, scapula, very deficient in mobility, but not anchored to the spine by any abnormal osseous or fibrous band.* Some of these cases present no curvature of the spine, and no abnormality of vertebræ and ribs, while others are complicated by scoliosis and

* It is this class which may be closely imitated by a case in which one scapula has become elevated as the result of poliomyelitis affecting the lower fibres of the trapezius and serratus magnus. It is well recognized that deficiency of muscles, particularly of the trapezius, frequently accompanies congenital elevation of the scapula. The fixation of the shoulderblade, the history, the absence of paralysis elsewhere, and frequently the radiographic appearances, will enable the congenital deformity to be distinguished from the acquired. 
CONGENITAL ELEVATION OF SCAPULA 563

an amount of irregularity of the upper ribs quite unexpected after an ordinary physical examination. Figs. 363 and 364 were taken from an example of

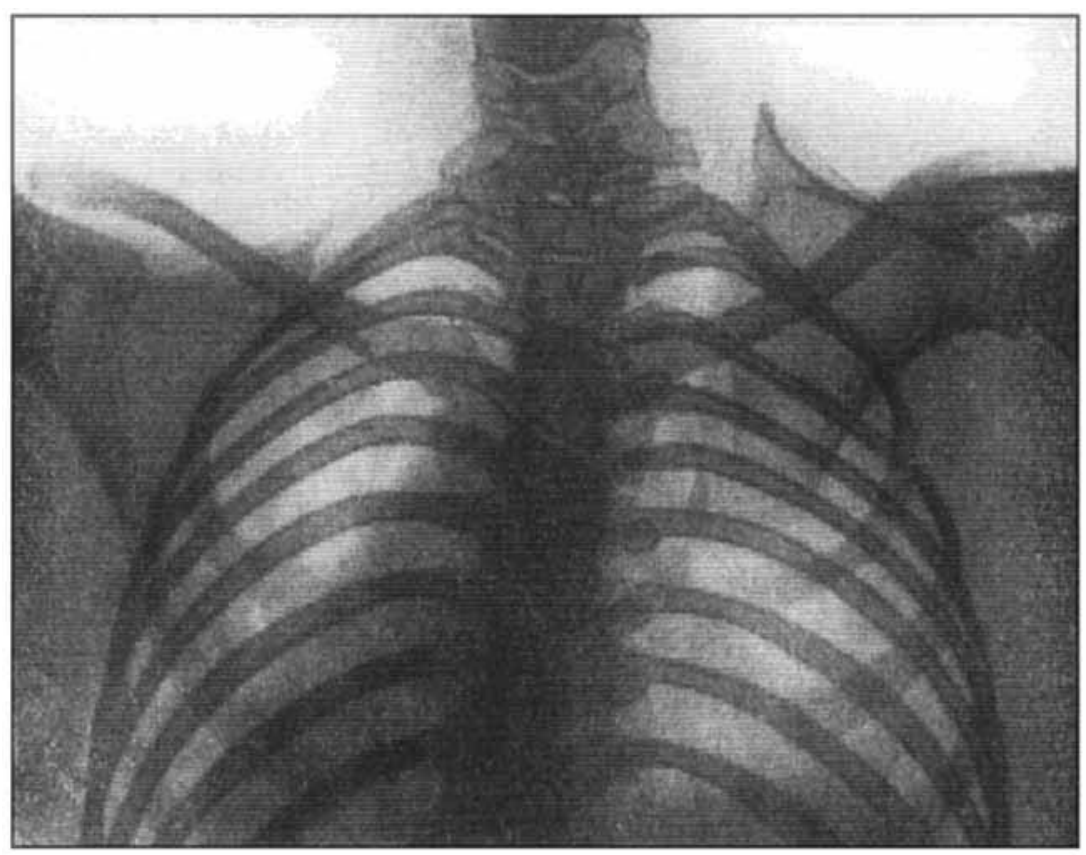

FIG. 364.-Case shown in Fig. 363. Note absence of deformity of spine and ribs. The transverse processes of the 7 th cervical vertebra are large, that on the left being worthy of the title "cervical rib."

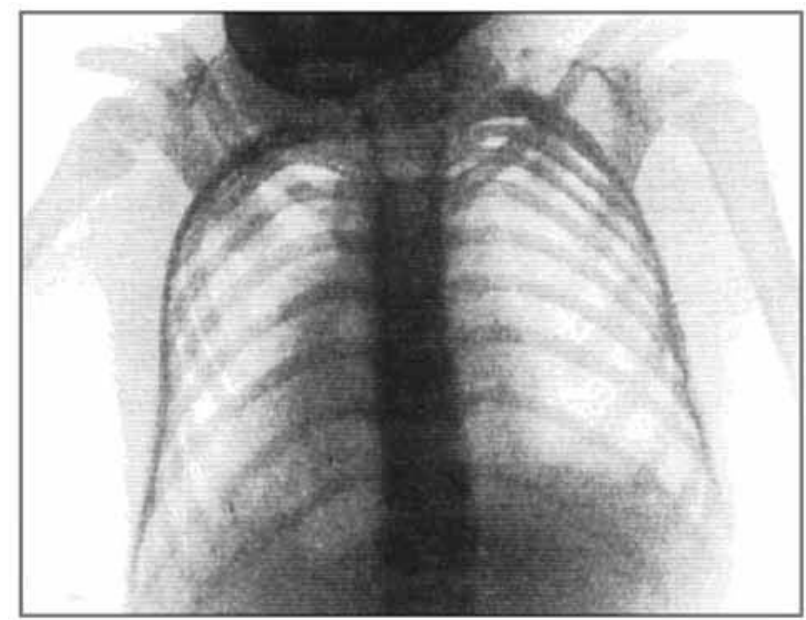

Fig. 365.-Girl, age 3, with bilateral elevation of scapulæ. The shortness of neck suggested suppression of cervical vertebræ, but this point could not be decided. 


\section{THE BRITISH JOURNAL OF SURGERY}

the first of these two groups The rough sketches make it clear how marked was the deformity, while the radiogram shows the absence of any changes in the bony skeleton. The right scapula was only slightly shortened in its vertical measurement, but its upper margin formed a pronounced prominence in the neck. It has been stated that in many cases the upper part of the scapular blade above the level of the spine is bent forwards, while in some cases the projection of the upper margin in the neck has been mistaken for a cervical rib. Case $\mathrm{I}_{5}$ is an example of bi-lateral elevation without gross vertebral mal-development, though the neck was

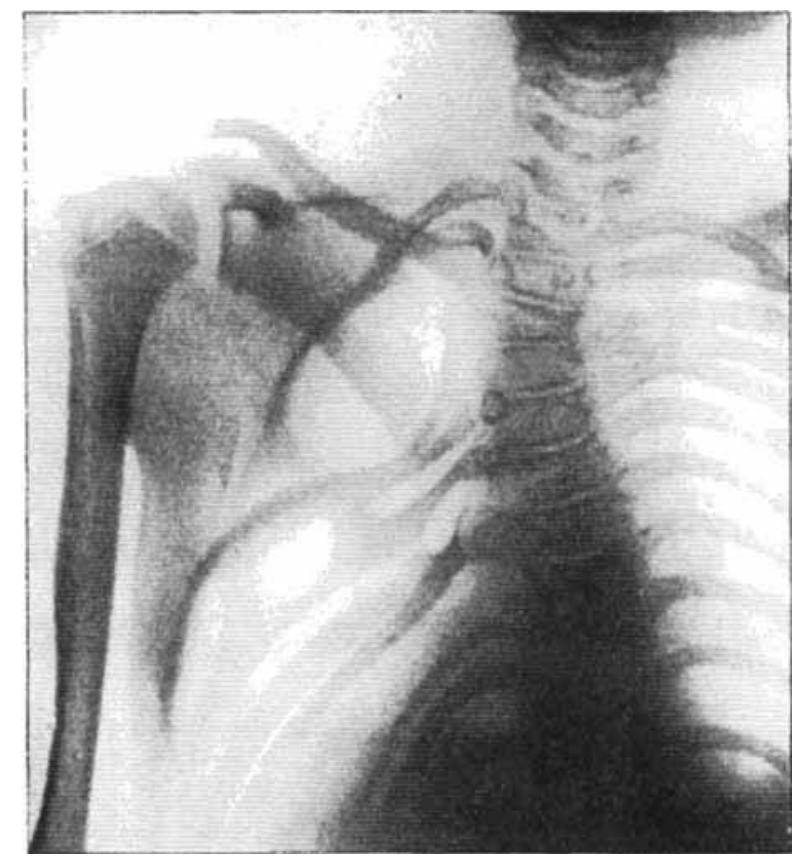

FIG. 366.-Case 3. Girl, age I2. Congenital elevation of left scapula, no bridge, congenital scoliosis and gross mal-development of ribs.

so short that suppression of cervical vertebræ was probably present, while the difficulties of taking a radiogram made it impossible absolutely to exclude rib deformity (Fig. 365). Fig. 366, taken from an example of the next group, shows elevation of an only slightly shortened, but definitely fixed, scapula, associated with very gross mal-development of ribs and congenital scoliosis, convex toward the affected shoulder. Cases 4 and 18 are also examples of this class. Figs. $367,368,369$, show the appearances seen in Case 3, with the arms in various positions.

Next in order, we find a congenitally elevated scapula with an exostosis projecting mesially from its vertebral border. There are two examples (Cases 6 and 9) in this series. 


\section{CONGENITAL ELEVATION OF SCAPULA 565}

Fig. 370 is a rough sketch of the right scapula of Case 6. Projecting from the vertebral border of the bone, about midway between the spinous process

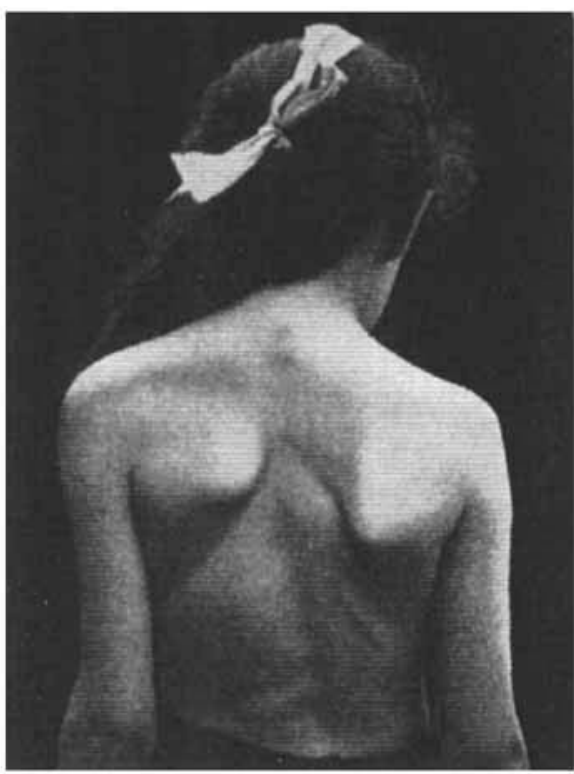

Frs. 367.-Case 3. Elevation of left shoulder. Radiogram seen in Fig. 366.

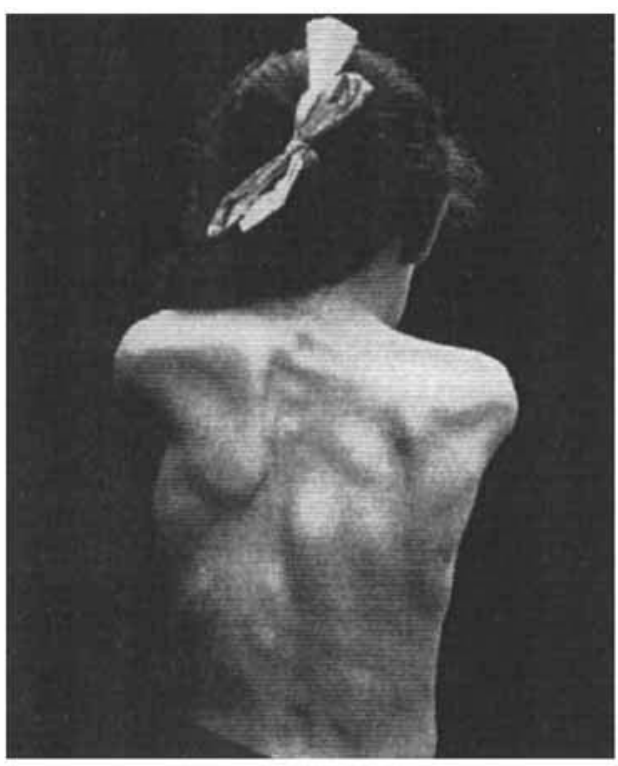
Fic. 369.-Case 3. With arms held horizontally
forward; note fixity of scapula.

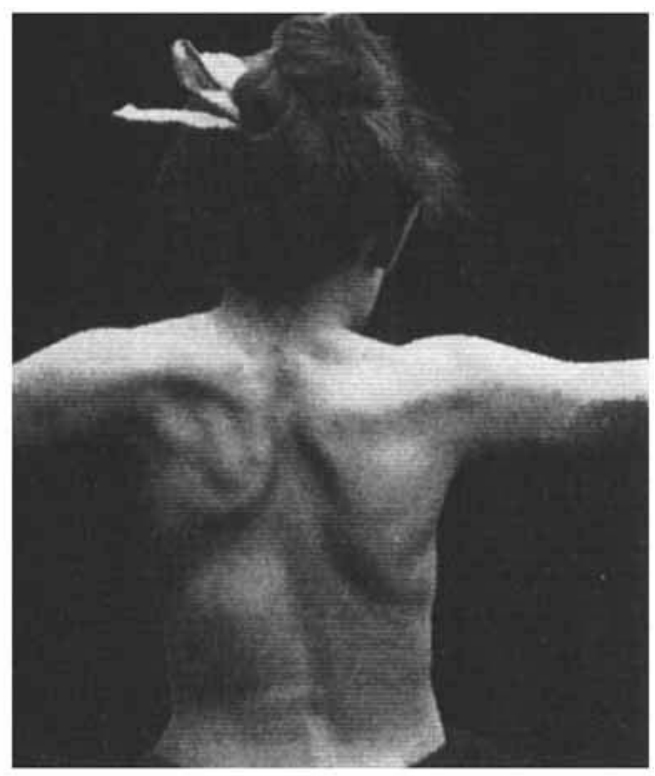

Fig. 368.-Case 3. With arms abducted.

and the inferior angle, is seen a hook-like exostosis. This process could be bent slightly on the rest of the bone, suggesting either that

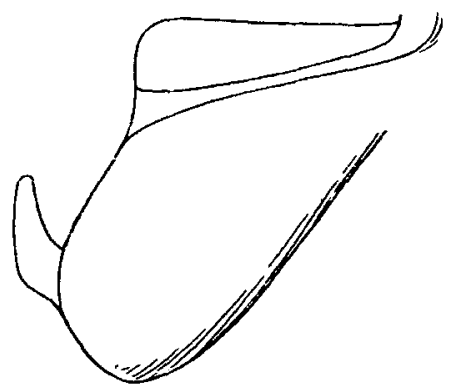
FIG. 370.-Diagram of right scapula
whth exostosis (Case 6 ).

it consisted of unossified cartilage, or that it was joined to the body of the scapula by a hinge of 
fibrous tissue. The skiagram (Fig. 37I) shows both scapulæ lying rather high, the right being the more elevated of the two, and in addition, it shows malformation of the upper dorsal spine, and suppression and fusion of ribs. Only eleven ribs can be made out on either side. On the right, the first rib is very slender, while the second and third, and the fourth and fifth, respectively, are partially fused. The head of the third is apparently absent.

Corresponding with this, the right half of the third dorsal vertebra also appears to be unformed, the left half being clearly distinguished. One and a half vertebræ have, therefore, been suppressed. If the skiagraphic appearances are read correctly, it is curious that no curvature of the spinal column is present.

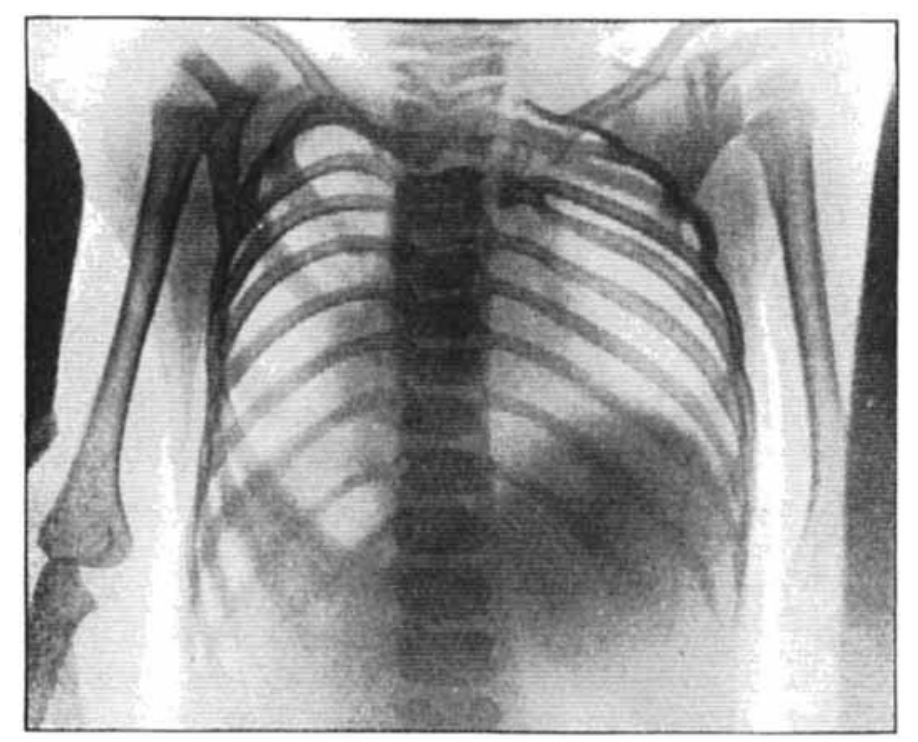

FIG. 371.-Case 6, from which Fig. 370 was drawn. Half-vertebra, fusion of ribs, etc.

In the other case of this kind (Case 9), the elevation of the left scapula was slight, but its position near the spinal column, its imperfect mobility, and its abnormal shape, justified the inclusion of the case in this series. Some mid-dorsal scoliosis was present, convex to the right. The left arm could not be raised to the vertical position. Projecting upwards and inwards from the vertebral border of the left scapula, just below the level of the spine, was a pointed process. This process was not unlike that in Case 6, but was attached at a somewhat higher level to the scapula, and was firmly welded to the rest of the bone. Its tip, which curled slightly upwards, yielded on pressure, and probably consisted of cartilage. There was no associated mal-development of ribs or vertebræ.

Reference may here be made to a case of exostosis of the sixth and seventh cervical spinous processes, shown by Mr. Maynard Heath ${ }^{3}$ in the Children's Section of the Royal Society of Medicine. The exostosis projected downwards and outwards in the direction of the scapula, which occupied a normal position. This case is interesting in view of the fact that the abnormal 
bridge of bone uniting some elevated scapulæ to the spine is regarded by a few as being of spinal and not scapular origin ( $\mathrm{J}$. Hutchinson, ${ }^{4}$ Wilson and Rugh ${ }^{5}$ ).

Lastly, we place the cases in which the scapula is anchored to the spinal column by an abnormal bridge consisting of fibrous tissue, cartilage, or bone. Besides the dissected specimen, described in detail above, there are six other cases in which an abnormal bridge of bone existed, and in one of these the abnormal bone was present on both sides (Cases 2, 5, 8, I0, I4, and I7). In all of these some slight amount of movement was allowed to the scapula, a sort of hinge being present between the bridge and the scapula on the onc hand, or the bridge and the

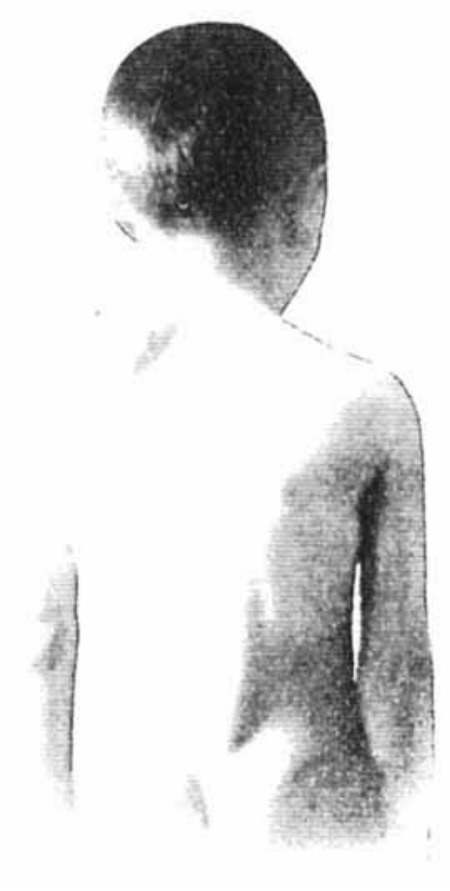

Fic. 372.-Case 8. Boy, age 7. Left scapula elevated and anchored to spine by bridge of bone, which is easily seen in the illustration.

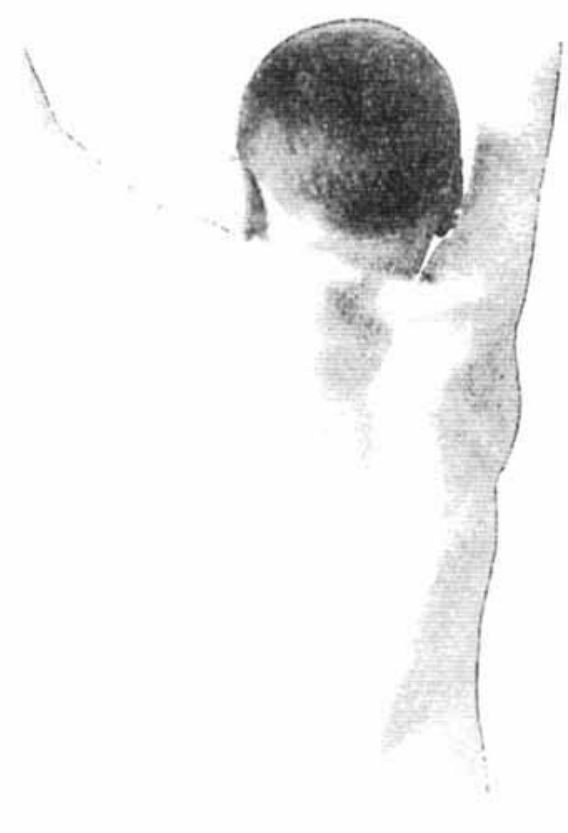

Fro. 373.-Case 8. The same boy, show. ing limitation of movement of arm typical of these cases.

spine on the other. If fusion had taken place at either end, the inner, i.e., the junction of bridge and spine, was the more likely site. In two cases, the bridge of bone was joined to the scapula by a hinge of elastic or fibrous tissue; in two by cartilage; in the rest, the exact bond of union was not ascertained. To the spine, the bridge was united by a hinge of fibrous tissue in two cases; in two cases osseous union had taken place; while in two there was a distinct attempt at an arthrodial joint. In Willet and Walsham's case, a woman, aged 3I, the bridge of bone was fused both with the scapula and the spine. Union by cartilage with the scapula, and bone with the spine, does not necessarily mean absolute fixation of the scapula, as was proved in Case ro during operation. The bridge is usually attached to 


\section{THE BRITISH JOURNAL OF SURGERY}

the vertebral border of the scapula, which may project out to meet it, either opposite the spinous process of this bone or a little below it. At the inner end, the bridge is connected with the lamina of one or more vertebræ near the transverse process, so that in some cases a connection, possibly a secondary one, takes place between the bridge and the transverse process. In Willet and Walsham's case the bridge is described as being fused with the spinous process and lamina of the sixth cervical vertebra. It would appear that the extremity of the spinous process, though possibly deviated from the mid-line, is usually

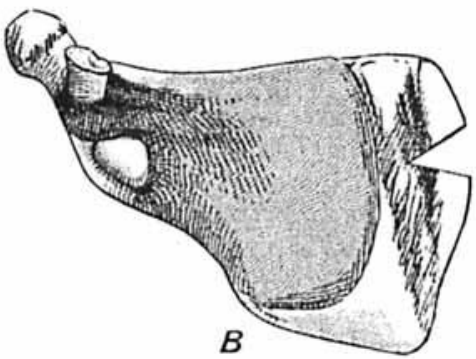

FIG. 371--Case 8. Bridge removed from between left scapula and spine. $A$, dorsal view; $B$, ventral view.

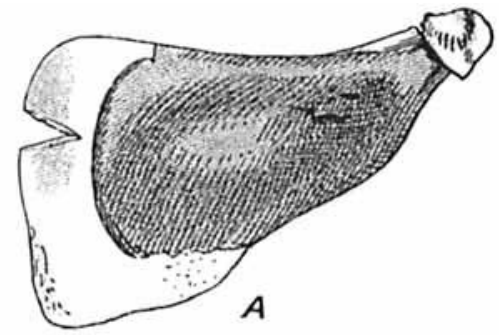

not connected with the bridge.

In three cases the abnormal bridge was removed by operation. The incision used was in one case $T$-shaped, and in the other two curved, the convexity of the curve being outwards ; the latter incision is the better.* Fig. 374 shows the bridge removed in the case of a boy of $7 \frac{1}{2}$ years. It measured $2 \frac{1}{2}$ in. transversely by nearly $\mathrm{I}_{2} \frac{1}{2}$ in. vertically. At the scapular end, a small portion of cartilage belonging to the scapula has been removed, and this portion is seen to be connected with the bridge by an imperfect hinge of yellow elastic tissue. At the inner end, two rounded articular processes are seen, the more superficial of which articulates by means of an arthrodial joint with the lamina of one of the lower, (?) sixth or seventh, cervical vertebræ. The other smaller process, situated on the deep aspect of the bone and nearer its upper border, articulated with the transverse process of the same vertebra, the lower margin gave attachment to some strong tendinous fibres which passed inwards and slightly upwards to the vertebra immediately below the one which actually articulated' with the bridge. During the removal of this portion of the bone it was found uncovered by anything but skin and subcutaneous tissue. Arising from its upper margin were some horizontal muscular fibres, evidently belonging to the trapezius as in the dissected specimen (Case II). Some vertical muscle fibres were inserted into its lower margin, presumably belonging to the erector spinæ. The deep aspect was practically free from muscular attachment and shelled readily.

Case Io, a child of I9 months, was also subjected to operation, the portion of bone removed being seen in Fig. 375. It measured $\mathrm{I}_{\frac{1}{\varepsilon}}$ in. by $\mathrm{I}_{\frac{1}{4}}$ in. The junction with the scapula was by cartilage, which was cut through in the

* Figs. 372 and 373 show a case of this kind, the second showng the amount of limitation of elevation of the arm. The position and relative size of the "bridge " can be made out in both. 


\section{CONGENITAL ELEVATION OF SCAPULA 569}

removal of the bone, no sign of a hinge being present. At the inner end the bridge was fused, i.e., there was bony union, with the junction of lamina and transverse process, this union being divided with bone-forceps. A feature of the case was the extraordinary mobility of the bndge, although absolutely fused with the fifth cervical vertebra. In this case the bone was overlaid by a partly aponeurotic and partly muscular trapezius, some hornzontal deeper fibres of which arose from the upper margin of the bridge as in the preceding case. The erector spinæ was attached to its lower margin, and had to be divided. while some fibres passed into its deep aspect, the exact nature of which it was impossible to detcrmine.

A third and last case was very similar to the preceding. The child's age was the same, the deformity was on the left side, while in each there was a dimple just below the spinous process and just outside the attachment of the bridge to the vertebral border of the scapula. In this case (Case I 7 ) the trapezius, though obviously not extending downwards to its normal extent, overlapped the upper part of the bridge, and again some fibres were seen arising from the upper margin of this abnormal structure. Some vertical fibres, presumably the levator anguli scapulæ, werc attached to the vertebral border above the bridge and to the upper margin of the bridge. These fibres were completcly divided. The rhomboidcus major was recognized bclow the bridge, and divided close to the scapula. The superficial fibres of the erector muscle ending in the lower margin of the bridge worc divided. The deep aspect was free from

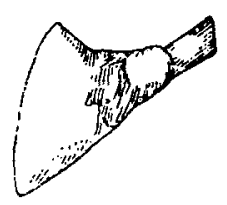

Fig. $376 .-$ Case I 7 Bridge of partially ossified cartilage removed by operation from betwcen lett scapula and spine.
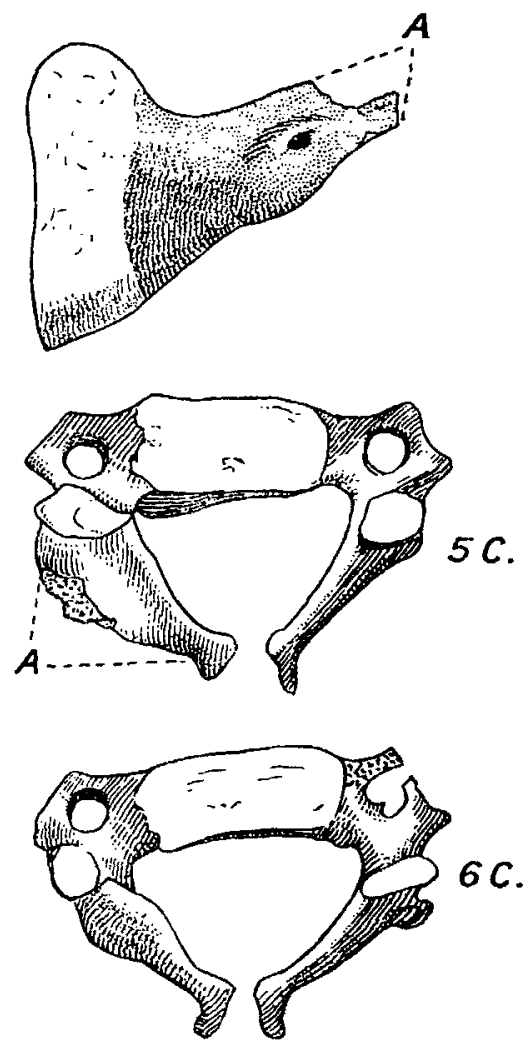

Fic. 375.-Bridge removed from child of ro months, also 5 th and 6 th cervica! vertebra obtaned later. A marks the position of the attachment of the bridge to the 5 th cervical vertebra. Failure of union in the neural arches of both vertebra is seen. some fibres of the serratus magnus arose from it. The cartilaginous union of the bridge to the scapula was divided, the complete clearing of the vertebral border of the scapula being thereby accomplished. The increased mobility the scapula was then capable of was obvious. At the inner end the bridge turned abruptly forwards as a cylindrical process of bone which passed directly into the bony lamina of a lower cervical vertebra near the point of origin of the transverse process. Bone-forceps were applied close to the lamina, and the bridge was removed. When seen recently, the improvement in vol. 1.-NO. 4. 


\section{THE BRITISH JOURNAL OF SURGERY}

the relative position of the shoulders was very marked. The appearance of the bridge after removal is seen in Fig. 376 .

The chief features of the whole series of 18 cases of congenital elevation of the scapula may be summarized as follows. The sex of 8 was male, of ro female. The right scapula was affected in 6 cases, the left in 9 , while in 3 the deformity was bilateral. The scapula was anchored to the spine in 7 cases: in 2 of these, both scapulæ were fixed, in one by a bridge of bone on both sides, and in the other by bone on the right and fibrous tissue on the left. Scoliosis was present in ro. In at least 4 a wedge-shaped half-vertebra was present. In one of these, at the age of two years, there was no curve, but by six years a low dorsal curve, towards or rather below the elevated scapula, and quite unconnected with the halfvertebra, had developed. In 5, the dorsal convexity was directed towards the raised shoulder, in 4 away from it, while in one case with an abrupt curve, both scapulæ were elevated. Partial fusion of ribs was seen in 7 cases, one of these being open to doubt. An unmistakable cervical rib was present in 2 cases only. In 2 there was total suppression of one or more vertebræ, while in 4 cases, including the two just mentioned, there was present a half- or wedge-shaped vertebra. In 3 other cases the shortness of the neck made suppression of vertebræ more than probable, but the difficulties encountered in taking radiograms prevented a definite decision being arrived at. In 2 cases a projection or exostosis was present at the vertebral border of the scapula.

With regard to other deformities present, 3 cases displayed torticollis, two of them having both scapula elevated. The radius was absent in $I$, the pectoral muscles were imperfect in 2 , and facial asymmetry was noted in 2 , only one of which was associated with torticollis.

Prognosis and Treatment.-Briefly stated, the prognosis and treatment. of the various conditions described above are as follows. In a curvature of the spine due to congenital malformation, exercises and manipulations should be employed as soon as the age of the child permits, with the view of limiting the amount of deformity and preventing the occurrence of secondary or acquired scoliosis. If such acquired curves are already present, and perhaps one shoulder thereby raised, the usual remedial treatment should be undertaken. In deciding the prognosis, it is of the utmost importance that the congenital origin of a portion of the deformity should be recognized, for this portion is usually not open to correction, whereas the acquired curves are, though the presence of the former will render the correction of the latter a matter of considerable difficulty. At any rate, the symmetry of the shoulders and the body generally can be considerably improved. In the cases of congenital elevation of the scapula, the spine always needs careful attention. If no curve is present at first, it may, and indeed is likely to, supervene later, so the closest watch should be kept upon the spine, deformity prevented by drill, and the slightest appearance of curvature checked by special exercises and other means. When congenital scoliosis complicates the elevation of the scapula, it should be treated as already suggested. As regards the elevation of the scapula, treatment never produces a very satisfactory improvement. If a definite bridge of bone or other tissue is anchoring the scapula to the spine, the bridge should undoubtedly be removed, and at the same time any muscles, such as the rhomboids and levator anguli scapulæ, which invite 
division, should be cut through. Such an operation will certainly improve the mobility of the shoulder and, to some extent, lessen the asymmetry, but judging from the photographs of reported cases, the result is always far from perfect. In cases in which no definite anchoring tissue can be felt, it is probably inadvisable to perform an operation.

In conclusion, I offer my thanks to those of my colleagues and others whose generosity has enabled me to collect this series of cases. Individual acknowledgement is made in the brief notes of the whole series, appended to this paper. In the majority of the cases the radiograms have been taken by Dr. Ironside Bruce.

\section{BRIEF NOTES OF CASES.}

Case I.-Male. 6 years, under the care of Dr. Lees, 1904, at Hospital for Sick Children, Great Ormond Street. Rught scapula elevated. Weakness of lower trapezıus and serratus on right side.

Case 2.-Female, 9 weeks, under the care of Mr. H. Stansfield Collier. Bilateral elevation of scapula. Both scapula anchored to spine by bridges of bone or cartilage. Right scapula short vertically, left well formed.

Case 3.-Female, I2 years, left scapula elevated. Congenutal scoliosis in upper dorsal region, convex to left but with rotation to right. Radiogram shows gross irregularity and fusion of ribs. Facial asymmetry. (Shown at Clinical Society in 1904.) (Figs. 365, 367, 368, 369.)

Case 4.-Female, 4 years, right scapula elevated. Slight rotation to right of vertebræ in dorsal region. Almost complete fusion of rst and 2nd right ribs. On right side, a band ran vertically from a point I inch to the right of the occipital protuberance to upper angle of scapula. This felt like a fibrosed muscle, (?) occipitoscapularis muscle. Scapula slightly short vertically. (Shown at Clinical Society in 1904.)

Case 5.-Male, in years. Left scapula elevated and anchored to spine by bony bridge. No malformation of vertebre or ribs. Movements of arms unusually free.

Case 6.-Male, 2 years. Right scapula elevated, short, and having exostosis projecting from vertebral border. No spinal curve when first seen; developed long right dorsal curve later : 2nd dorsal vertebra wedge-shaped, right half being absent, and there being only $9 \frac{1}{3}$ dorsal vertebra all told. Ribs: Io on left. I I on right: fusion of and and $3^{\text {rdd, }}$ and $4^{\text {th }}$ and $5^{\text {th }}$ ribs on right. Neck very short. (Figs. $370,37 \mathrm{I}$.)

Case 7.-Female, 23 years, under care of Mr. Waterhouse at Charing Cross Hospital, for hernia in I904. Right scapula elevated, well formed. No abnormality of vertebra or ribs. Transverse processes of last cervical vertebra long, that on left deserving name of cervical rib. (Figs. $36^{6} 3,364$.)

Case 8.--Male, 7 years. Left scapula elevated, malformed, and anchored to spine by bridge of bone. Bridge removed by operation at Hospital for Sick Children, Great Ormond Street, in r9o8. Scoliosis, left dorsal, right lumbar. Absence of lower fibres of left trapezius. Irregularity ist and 2nd right ribs. Case lost sight of after operation. (Figs. 372, 373, 374.)

Case 9.-Female, 8 years. Left scapula malformed, slightly elevated, and displaying exostosis at vertebral border. Right dorsal scoliosis. Muscles, vertebræ and ribs normal.

Case ro.-Female, 18 months. Left scapula elevated, fanly normal in shape. but anchored to spine by bridge of bone. Skin dimpled over scapula. Bridge removed by operation at Hospital for Sick Children, Great Ormond Street, in I9I0. Right dorsal curve in spine below bridge. No malformation of vertebra and ribs in radiogram. Child died of menungitis. (Fig. 375.)

Case i r.-Female, 6 weeks. Case reported in detail above. (Figs. 355-359.) 


\section{THE BRITISH JOURNAL OF SURGERY}

Case 12.-Male, 8 years. Right scapula elevated, slightly short vertically. Partial absence of pectoralis major, and total absence of pectoralis minor, of right side. Slight right dorsal left lumbar scoliosis, but left ribs prominent behind, the right side being distınctly smaller than the left. No abnormality of vertebræ or ribs. (Under the care of Mr. J. Pardoe at West London Hospital, and kindly referred for examination.)

Case 13.- Male, 3 years. Right scapula elevated. No scoliosis. Lower half of pectoralis major absent on the right. Serratus very feeble or absent. Radiogram not taken. Case was lost sight of before full investigation had been completed, so the congenital origin of the deformity is doubtful.

Case 14.-Female, 3 years. Left scapula small and elevated, and anchored to spine by bridge of bone. Left torticollis, with facial asymmetry. Left thumb diminutive. Radiogram not taken.

Case I5.-Femalc, 3 years. Bilateral elevation of scapulæ. Neck very short, suggesting suppression of cervical vertebræ. Impossible to decide by $x$-rays whether vertebræ and upper ribs normal or not. Left arm small and humerus slender. (Kindly referred by Mr. O. L. Adison.) (Fig. 365.)

Case I6.-Female, I 7 years. Left scapula normal in shape and mobility, but elevated. Small abiupt congenital spinal curve to left in upper dorsal region, and similar sharp curve to left in lumbar. Thild dorsal vertebra wedge-shaped, the right half being absent. Second lumbar mis-shapen. Ribs: $3^{\text {rd }}$ right absent; $5^{\text {th }}$ and 6 th right fused for 2 inches; $3^{\text {rd }}$ and $4^{\text {th }}$ left fused for a short distance. (Figs. 362, 362a.)

Case I7.-Male, I9 months. Left scapula malformed, elevated, and anchored to spine by bridge of bone. Skin dimpled over junction of bridge and scapula, which junction stood out prominently. Bridge removed at Hospital for Sick Children, Great Ormond Street, in I9I3. No scoliosis. No mal-development of vertebræ and ibs except (?) fusion of 2 cervical laminæ on left. (Kindly referred by Mr. H. Tyrrell Gray.) (Fig. 376.)

Case I 8.-Male, I2 years. Left scapula well formed but much elevated. Spine excurvated from 7 th celvical to 8th dorsal, and rigid. Anterior end of 3 rd left rib very prominent. Right dorsal, left lumbar scoliosis. Radiogram shows balf-vertebra, deficiency right $4^{\text {th }} \mathrm{rib}$, and presence of cervical rib on right. (Case kindly referred by Dr. Poynton.)

\section{REFERENCES.}

1 Trans. Med. Chrr. Soc., I88o, 1xiii, and 1883 , lxvi.

2 Arch. f. klin. Chiv., I89 I, Bd. 42.

${ }^{3}$ Roy. Soc. Med., Sect. Dis. of Children, rgा I, April.

4 Path. Soc. Trans., $1894,136$.

'Ann. Surg.. J900, 4 fig. 